\title{
TU/e EmonOWEN

\section{A new method for sorptive enrichment of gaseous samples: Application in air analysis and natural gas characterization}

\section{Citation for published version (APA):}

Baltussen, H. A., Janssen, J. G. M., Sandra, P. J. F., \& Cramers, C. A. M. G. (1997). A new method for sorptive enrichment of gaseous samples: Application in air analysis and natural gas characterization. Journal of High Resolution Chromatography, 20(7), 385-394. https://doi.org/10.1002/jhrc.1240200708

DOI:

10.1002/jhrc. 1240200708

Document status and date:

Published: 01/01/1997

\section{Document Version:}

Publisher's PDF, also known as Version of Record (includes final page, issue and volume numbers)

\section{Please check the document version of this publication:}

- A submitted manuscript is the version of the article upon submission and before peer-review. There can be important differences between the submitted version and the official published version of record. People interested in the research are advised to contact the author for the final version of the publication, or visit the $\mathrm{DOI}$ to the publisher's website.

- The final author version and the galley proof are versions of the publication after peer review.

- The final published version features the final layout of the paper including the volume, issue and page numbers.

Link to publication

\section{General rights}

Copyright and moral rights for the publications made accessible in the public portal are retained by the authors and/or other copyright owners and it is a condition of accessing publications that users recognise and abide by the legal requirements associated with these rights.

- Users may download and print one copy of any publication from the public portal for the purpose of private study or research.

- You may not further distribute the material or use it for any profit-making activity or commercial gain

- You may freely distribute the URL identifying the publication in the public portal.

If the publication is distributed under the terms of Article 25fa of the Dutch Copyright Act, indicated by the "Taverne" license above, please follow below link for the End User Agreement:

www.tue.nl/taverne

Take down policy

If you believe that this document breaches copyright please contact us at:

openaccess@tue.nl

providing details and we will investigate your claim. 


\section{A New Method for Sorptive Enrichment of Gaseous Samples: Application in Air Analysis and Natural Gas Characterization}

Erik Baltussen*, Hans-Gerd Janssen, Pat Sandra, and Carel A. Cramers

Eindhoven University of Technology, Laboratory of Instrumental Analysis, P.O. Box 513, 5600 MB Eindhoven, The Netherlands

\section{Key Words:}

Sorptive preconcentration

Thermal desorption

Air enrichment

Environmental samples

Natural gas

PAHs

Nitro-PAHs

\section{Summary}

A new method for the preconcentration of trace components from gaseous samples is described. The system is based on enrichment of the solutes on a packed bed of $100 \%$ polydimethylsiloxane (PDMS) particles followed by thermal desorption and GC analysis. It was demonstrated that breakthrough volumes for packed PDMS traps can be calculated from theoretical equations. The PDMS material exhibits excellent thermal stability even after 200 consecutive runs. Additional advantages of packed sorbent beds over conventional adsorbent materials include high inertness, the absence of displacement effects and a reduced affinity for water. The practicality of the system was demonstrated by the analysis of air and natural gas. Using the system described here, components in the range of octane to benzo[ $a]$ pyrene could be quantitatively trapped and thermally desorbed at mild temperatures. With the present set-up the detection limit is in the order of $0.1 \mathrm{ng} / \mathrm{m}^{3}$ (MSD detector).

\section{Introduction}

The vast majority of analytical procedures currently in use for the preconcentration of volatile organic components in air is based on adsorption of the analytes of interest on a suitable adsorption material. The most popular adsorbent materials are carbon-based materials such as activated charcoal [1-3] or carbon molecular sieve [1] and porous organic polymers, for example Tenax [4-6]. These are all strong adsorption materials with high surface areas $\left(>10 \mathrm{~m}^{2} / \mathrm{g}\right)$ and give excellent performance for preconcentration of (highly) volatile apolar compounds. Unfortunately, their applicability for the analysis of polar and/or high molecular weight components is limited. Polar solutes for example, can be easily adsorbed but they can also readily be converted on the surface catalyzed by active surface groups [7]. High molecular weight components cannot be desorbed due to the extremely strong interaction with the adsorbent. In conclusion, the applicability of conventional adsorption materials for the analysis of high molecular weight and/or unstable molecules is often cumbersome. For such solutes, artifact formation is likely to occur rendering accurate identification and quantification difficult at best.

Recently an alternative method for the preconcentration of organic components in air was described by Burger and Munro [8] and Roeraade and Blomberg [9]. In this method an open-tubular trapping column containing a thick film of a GC stationary phase coated onto the wall is used for sample enrichment. Preconcentration of the analytes occurs by sorption of the components into the liquid phase rather than by adsorption onto an adsorbent. Preconcentration by sorption or partitioning into a thick-film of a polysiloxane liquid phase has a number of advantages over adsorption onto an active packing material. In the sorption method, high molecular weight components (e.g. benz [a]pyrene) can be desorbed at mild temperatures. Secondly, as the energy of partitioning is lower than typical adsorption energies, the thermal stress applied to the molecules upon desorption is minimized. Moreover, the material used is much more inert than a standard adsorbent, thereby reducing the risk of losses of unstable and/or polar analytes by irreversible adsorption or by catalytic reactions on the surface. Displacement effects are unlikely to occur in the sorption mode of preconcentration and sorption isotherms are linear up to very high concentrations. Major advantages of polysiloxane materials over classical carbon based adsorbent materials is the fact that water is not retained by the siloxane material [10] and that degradation products of the material can be easily recognized with the use of a mass selective detector as they will contain characteristic silicone mass fragments. Finally, it is possible to calculate the retention volume of a certain compound from GC retention data (i.e. Kovats retention indices) which are known for numerous compounds and are relatively easy to determine using standard GC instrumentation. This eliminates the need to determine the breakthrough volume for each individual component as is for example the case with Tenax $[11,12]$.

The use of thick film open-tubular traps as preconcentration devices for real-world samples was demonstrated by Burger and Munro for the analysis of wine headspace [8]. Roeraade and Blomberg used it for the analysis of Stockholm air [9] whereas Bicchi et al. applied enrichment in thick film open tubular traps for the analysis of volatiles emitted by living plants [13]. Despite the evident advantages of preconcentration by sorption, the technique never gained widespread acceptance. This is largely due to the fact that until now true sorptive preconcentration could only be performed in open-tubular traps. These devices, however, suffer from two clear disadvantages, i.e. a low total (volume) capacity and a low maximum allowable sorption flow rate (usually $1-10 \mathrm{ml} / \mathrm{min}$ ). In an attempt to overcome these problems Ortner and Rohwer [14] have designed a multichannel thick film silicone trap. This device consists of several polysiloxane tubes in parallel fitted in a glass tube suited for thermal desorption in the injector. Unfortunately, even with this system the maximum flow rate that can be used while still maintaining acceptable breakthrough volumes is only about $15 \mathrm{ml} / \mathrm{min}$. Krieger and Hites [15] designed a multi-channel open tubular trap consisting of a 
bundle of DB-1 coated capillaries. They were able to achieve sampling flow rates up to $1.5 \mathrm{l} / \mathrm{min}$

In this contribution the applicability of a packed bed containing $100 \%$ polydimethylsiloxane (PDMS) particles for use as a sorption device in the enrichment of gaseous samples is investigated. The analytes from a gaseous sample are first trapped on the PDMS preconcentration trap. Subsequently the trap is heated and the analytes are thermally desorbed onto the GC column. A theory model is derived that allows the prediction of breakthrough volumes from gas chromatographic retention data and trap properties. The applicability of the system is demonstrated by the analysis of various environmental and industrial samples.

\section{Theory}

Sampling in (ad)sorption/thermal desorption systems for air enrichment is usually performed in the breakthrough sampling mode. In this sampling mode, air is sampled through the preconcentration device until the most volatile compound is no longer quantitatively retained by the sorbent and starts to elute (or break through) from the trap. This implies that the breakthrough volume of the trap, i.e. the volume of air that can be passed through the trap before breakthrough starts to occur, is determined by the most volatile compound. Less volatile compounds are still far from breakthrough. The potentially higher sensitivity for these solutes cannot be achieved due to breakthrough of the least volatile analyte. Below, the sorption characteristics of PDMS packed sorption tubes are addressed.

The required minimum breakthrough volume can be estimated from the desired concentration detection limits and the detector sensitivity. As an example, for the determination of pesticides in air, a minimum detectable concentration of at least $1 \mathrm{ppt}\left(1 \mathrm{ng} / \mathrm{m}^{3}\right)$ is desired [16]. If an FID detector is used, roughly $0.5 \mathrm{ng}$ of solute is required for accurate peak recognition and integration. This implies that 500 liters of air need to be sampled onto the trap, i.e. the breakthrough volume should be more than $500 \mathrm{l}$. From the flow rate applied, the total sampling time required can be calculated. If air is sampled at a 'normal' flow rate of $100 \mathrm{ml} / \mathrm{min}$, sampling 5001 of air would take $5000 \mathrm{~min}$, which is, of course, unacceptably long. Below, the possibility of using high sampling flows (up to $5 \mathrm{l} / \mathrm{min}$ ) is investigated.

In order to fully apprehend the possibilities of packed PDMS sampling tubes it is necessary to investigate the retention volume and especially the breakthrough volume of compounds on these traps. According to the theory described by Lövkvist and Jönsson [17] the breakthrough volume of an enrichment $\operatorname{trap}\left(V_{\mathrm{b}}\right.$, allowing $5 \%$ breakthrough) is given by:

$V_{\mathrm{b}}=V_{0} \times(1+k) \times\left(0.9025+\frac{5.360}{N}+\frac{4.603}{N^{2}}\right)^{-0.5}$

Here $V_{0}$ is the trap dead volume, $k$ the capacity factor, and $N$ the plate number of the trap. $V_{0}$ is a trap specific parameter, the capacity factor is a thermodynamic parameter depending on the solute, trapping material, phase ratio of the trap, and on the temperature. The plate number is a kinetic parameter that depends on the flow rate in the trap and on solute and trapping material properties.
The breakthrough level is defined as the amount of analyte that has eluted from the trap relative to the amount of analyte that has been sampled. If the sampling flow rate is kept constant, the breakthrough level is given by:

$b=\frac{\text { total amount of analyte eluted from trap }}{\text { total amount of analyte sampled }}=\frac{\int_{0}^{t} C_{0}(t) \mathrm{d} t}{\int_{0}^{t} C_{i}(t) \mathrm{d} t}$

Where $C_{\mathrm{o}}(t)$ is the concentration in the gas leaving the trap outlet and $C_{\mathrm{i}}(t)$ is the concentration in the gas entering the trap.

The capacity factor can be calculated from:

$k=\frac{K}{\beta}$

In this equation $\beta$ is the phase ratio of the trap which can be determined experimentally or can be calculated as will be demonstrated later. For alkanes the values for the equilibrium distribution coefficient $(K)$ can be obtained from the equation published by Millen and Hawkes [18]:

$K=\exp \left(\frac{950+905 \times C}{1.987 \times T}-0.59 \times C-1.8\right)$

Here $T$ represents the absolute temperature and $C$ is the carbon number of the alkane. The last parameter in eq. (1), $N$, can be calculated from the well-known Knox equation $[19,20]$ :

$h_{r}=3 v^{1 / 3}+\frac{1.5}{v}+0.05 v$

with:

$h_{r}=\frac{H}{d_{\mathrm{p}}}=\frac{L}{N d_{\mathrm{p}}}$

$v=\frac{u d_{\mathrm{p}}}{D_{\mathrm{m}}}$

Where $H$ is the plate height, $d_{\mathrm{p}}$ is the particle diameter, $u$ is the linear velocity during sampling, $L$ is the length of the packed bed, and $D_{\mathrm{m}}$ is the diffusion coefficient in the gas phase. A method for the estimation of $D_{\mathrm{m}}$ values has been published by Fuller $e t$ al. [21].

From eq. (5) it can be seen that at high sampling velocities (i.e. high sampling flow rates) the reduced plate height will be very high and hence the plate number will be very low. Using equation 1 the breakthrough volume of a trap can be calculated as a function of the plate number. Figure 1 shows the calculated breakthrough volume as a function of $\mathrm{N}$ for a trap with a dead volume of $1 \mathrm{ml}$ and a solute with a capacity factor of $1 * 10^{6}$. From Figure 1 it is clear that even at very low plate numbers reasonable breakthrough volumes can still be obtained.

To illustrate the possibilities of packed PDMS sampling tubes the presented theory is used to calculate the breakthrough volume for pentadecane. For this solute, eq. 4 yields an equilibrium constant of $1.62 \times 10^{6}$ at $20^{\circ} \mathrm{C}$. If a preconcentration tube is used with a dead volume of $1 \mathrm{ml}$ and a phase ratio of 1 this leads to a retention volume of 1621 liters. Typical values for $d_{p}$ and the inner diameter of the sampling tube are 0.5 and $4 \mathrm{~mm}$, respec- 


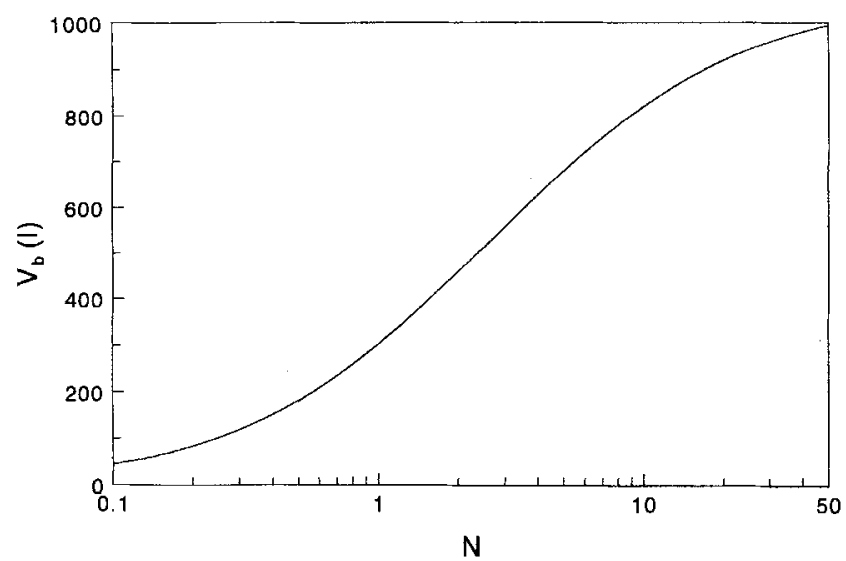

Figure 1. Breakthrough volume as a function of the number of theoretical plates according to the theory of Lövkvist and Jönsson [17]. $V_{0}=1 \mathrm{mi}, k=1 \times 10^{6}$.

tively. A typical bed length is $5 \mathrm{~cm}$. If a sampling flow rate of $1500 \mathrm{ml} / \mathrm{min}$ is used this results in a reduced velocity of 420 and a plate number of 2.3 ( $D_{\mathrm{m}}$ for pentadecane in air is estimated to be $5.8 \times 10^{-6} \mathrm{~m}^{2} / \mathrm{s}$ ). Even at this very low plate number, eq. (1) yields a breakthrough volume of 800 liters. This means that a detection limit of $1 \mathrm{ppt}$ can be obtained for pentadecane using an FID detector.

The approach presented above only allows the calculation of breakthrough volumes for alkanes. In order to be able to estimate the break through volume for other (non-alkane) solutes a universal equation for the calculation of equilibrium constants has to be derived. This can be done using the well known Kovats retention indices $(R I)$ which are available for numerous compounds and are easy to determine experimentally. The Kovats retention index is defined as:

$$
\begin{aligned}
R I & =100 \times \frac{\log \left(t_{\mathrm{A})}^{\prime}-\log \left(t_{\mathrm{Z})}^{\prime}\right.\right.}{\log \left(t_{\mathrm{Z}}^{\prime}+1\right)-\log \left(t_{\mathrm{Z}}^{\prime}\right)}+100 \times Z= \\
& =100 \times \frac{\log \left(K_{\mathrm{A})}-\log \left(K_{\mathrm{Z})}\right.\right.}{\log \left(K_{\mathrm{Z}+1}\right)-\log \left(K_{\mathrm{Z}}\right)}+100 \times Z
\end{aligned}
$$

Where $Z$ is the number of carbons in the $n$-alkane eluting just before the compound of interest (A). $t_{1}$ 'is the net retention time and $K_{\mathrm{i}}$ is the equilibrium constant of the component $i$. Using this definition the equilibrium constant for a given component can be calculated from:

$\log \left(K_{\mathrm{A}}\right)=\log \left(K_{\mathrm{Z}}\right)+\left(\frac{R I}{100}-Z\right) \times\left(\log \left(K_{\mathrm{Z}}+1\right)-\log \left(K_{\mathrm{Z}}\right)\right)$

The procedure to calculate $V_{\mathrm{b}}$ for a non-alkane is to first look up the retention index of this solute at the trapping temperature in published data sets, then calculate $K_{\mathrm{Z}+1}$ and $K_{\mathrm{Z}}$ with eq. (4) and calculate $K_{\mathrm{A}}$ with eq. (9). At the sampling flow rate chosen, calculate $u$ and with eq. (5) through (7) calculate $N$. Finally, eq. (1) yields $V_{\mathrm{b}}$. If the retention index value at the trapping temperature is not available, the retention index at the nearest available temperature can be used. For the $100 \%$ methyl silicone trap used this will not result in a large deviation as the temperature dependence of the retention index on such phases is generally small.

\section{Experimental}

As was already pointed out by Grob and Habich [22], the main problem when interfacing a packed preconcentration column with a high resolution capillary GC column is the flow incompatibility between the trap and the GC column. The flow rate through the GC column is of the order of $1-5 \mathrm{ml} / \mathrm{min}$ whereas the flow through the trap is in the range of $30-300 \mathrm{ml} / \mathrm{min}$. Obviously, transfer of the analytes from the trap to the column cannot be accomplished by directly linking the trap to the column. Although Grob and Habich preferred to use capillary preconcentration traps instead of packed traps, there are two basic solutions to the flow incompatibility problem. The first solution is to split the flow exiting the preconcentration trap and allowing only a few $\mathrm{ml} / \mathrm{min}$ to enter the column. In this way most of the sample is vented which, obviously, results in a significant loss in sensitivity. This mode is called split desorption.

The second solution is to use a thermal desorption system containing two split points and a capillary cold trap between these split points. This approach will be discussed in more detail later. With this set-up it is possible to transfer the analytes of a packed preconcentration tube splitless onto the column at flow rates up to $250 \mathrm{ml} / \mathrm{min}$. This flow mode is called splitless desorption. Both split and splitless transfer are used in the present study.

\subsection{Packed PDMS Traps}

The packed PDMS preconcentration tubes used for all experiments were prepared from glass tubes with an inner diameter of $4 \mathrm{~mm}$. This glass tube was filled with PDMS particles prepared by grinding Silastic ${ }^{\circledR}$ silicone laboratory tubing (Dow Corning, Midland, MI, USA) under liquid nitrogen. The dimensions of this high purity $100 \%$ polydimethylsiloxane tubing were $0.63 \mathrm{~mm}$ o.d. and $0.3 \mathrm{~mm}$ i.d. The average particle size of the prepared PDMS particles is roughly equal to the outside diameter of the starting material $(0.63 \mathrm{~mm})$. It is important to realize that the PDMS phase is not coated onto any kind of support material which can exhibit undesired adsorptive and catalytic properties. The density of the PDMS material was determined from the volume and weight of $50 \mathrm{~cm}$ of Silastic tubing and was found to be $0.825 \mathrm{~g} / \mathrm{ml}$.

The glass tube was filled with $0.325 \mathrm{~g}$ of PDMS particles which is equivalent to a volume of $0.394 \mathrm{ml}$. Since the PDMS bed was $5.8 \mathrm{~cm}$ long the trap dead volume $\left(V_{0}\right)$ is $0.334 \mathrm{ml}$. The phase ratio $(\beta)$ hence is 0.848 . The PDMS bed is kept in place by means of two small plugs of deactivated quartz wool (Chrompack, Middelburg, the Netherlands).

\subsection{Experimental Set-Up for Breakthrough Experiments}

Prior to starting actual air sampling experiments, the theory presented in the previous section for the calculation of breakthrough volumes was verified experimentally. The experimental set-up used in these experiments consisted of a Gerstel TDS-2 thermal desorption unit (Gerstel GmbH, Müllheim a/d Ruhr, Germany) mounted on top of an HP5890A GC (Hewlett Packard, Avondale, PA, USA). The system is schematically shown in Figure 2. 

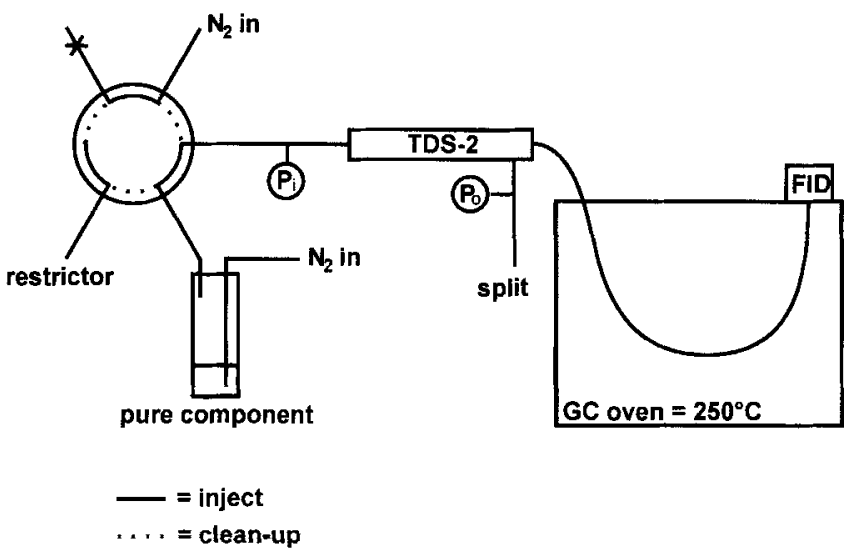

Figure 2. Experimental set-up used for the determination of the retention behavior of packed PDMS traps.

A short piece of $0.32 \mathrm{~mm}$ i.d. fused silica tubing was used to connect the outlet of the trap directly to the flame ionization detector. Since the flow rate to the detector cannot be too high, the gas stream leaving the sampling tube was split using the internal split of the TDS-2 system. The GC oven was kept at $250{ }^{\circ} \mathrm{C}$ during all experiments to prevent retention of the solutes in the 'transfer line'. A fast 6-way valve (Type WE-II, Valco, Houston, TX, USA) was used to inject a step concentration gradient onto the trap. Two pressure gauges $\left(\mathrm{P}_{\mathrm{i}}\right.$ and $\left.\mathrm{P}_{\mathrm{o}}\right)$ were used to measure the pressure drop over the sorbent bed. The temperature inside the trap was controlled with the TDS- 2 controller. This allows the calculation of pressure and temperature corrected flows inside the PDMS bed. The carrier gas was nitrogen which was purified using a P300-2 nitrogen purifier (UOP mat/sen, El Dorado Hills, CA, USA) specified to generate grade 7.0 nitrogen. Nitrogen was chosen because its diffusion characteristics are closest to those of air. Two nitrogen streams are supplied to the 6-way valve, one clean stream and one stream containing a low concentration of the test compound. The latter stream was prepared by bubbling nitrogen gas through the (liquid) test compound.

In a first series of experiments, the retention behavior of packed PDMS traps was investigated for four solutes. Experimental retention volumes $\left(V_{\mathrm{r}}\right)$ and plate numbers $(N)$ were determined for decane, 1-octanol, 2-nonanone, and dodecane.

Prior to the start of a breakthrough experiment the 6-way valve is in the clean-up position: the PDMS trap is flushed with ultraclean nitrogen to remove any residual compounds. At the start of an experiment the valve is switched to the inject position and spiked nitrogen is led onto the trap. The concentration in the outlet of the trap is monitored by the FID detector. From the recorded breakthrough curve the retention volume $\left(V_{\mathrm{r}}\right)$ and the number of theoretical plates $(N)$ can be calculated as will be explained later.

In order to minimize the system dead volume all tubing is kept as short as possible. Unfortunately, the system still has a considerable dead volume so that breakthrough curves can only be accurately recorded for compounds which are sufficiently retained (i.e. $k>500$ ). This is not a serious drawback since weakly retained compounds are less interesting due to their low retention volumes and consequently high minimal detectable quantities in actual air enrichment.

\subsection{On-Line Sampling/Split Desorption}

Split desorption is the simplest and most straight-forward method to transfer analytes from a packed preconcentration device onto a capillary analytical column. It is particularly useful for concentrated samples. In the present work split desorption was applied for the analysis of higher MW alkanes in natural gas. The experimental set-up used is shown in Figure 3. It consists of the Gerstel TDS-2 thermal desorption unit, a CIS-3 PTV injector (Gerstel) and an HP5890A GC.

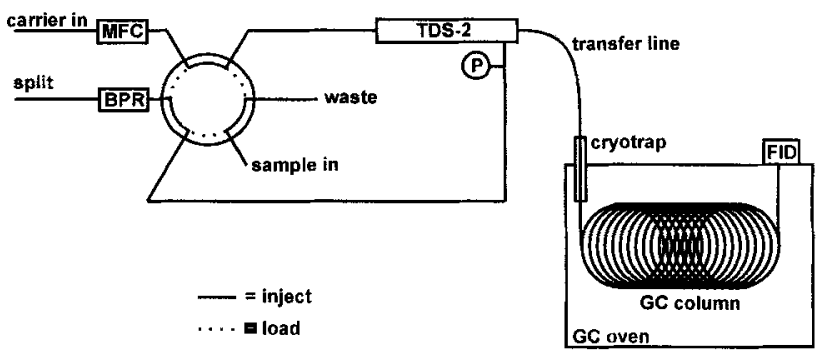

Figure 3. Experimental set-up for split desorption. Carrier $=$ helium, $\mathrm{MFC}=$ mass flow controller, $\mathrm{BPR}=$ back pressure regulator, $\mathrm{P}=$ pressure gauge.

The analytical column was connected directly to the TDS-2, the CIS-3 functioned merely as an on-column cold trap. The transfer line through which the column is connected to the TDS-2 is kept at $250{ }^{\circ} \mathrm{C}$ during all experiments. With the system shown in Figure 3 it is possible to load the PDMS trap at sub-ambient temperatures (down to $-50^{\circ} \mathrm{C}$ with liquid nitrogen cooling) providing increased retention power. However, in case of humid samples care has to be taken to prevent water from condensing (or freezing) inside the trap. Helium is used as the carrier gas in all experiments. It is purified by means of a P100-2 helium purifier (UOP mat/sen) specified to generate grade 7.0 helium.

Prior to a run the valve is in the inject position. Before sampling is started, the TDS- 2 is cooled to the sampling temperature (usually $0-25^{\circ} \mathrm{C}$ ). The valve is then switched to the load position and the sampled is fed onto the PDMS trap. Two minutes before sampling is complete, the cryotrap is cooled to its initial temperature (usually $-150^{\circ} \mathrm{C}$ ). On completion of sampling the valve is switched back to the inject position and the PDMS trap is thermally desorbed with helium. Finally, the sample was analyzed on a CP Sil $5 \mathrm{CB}$ column with an inner diameter of $320 \mu \mathrm{m}$, a film thickness of $1.1 \mu \mathrm{m}$, and a length of $35 \mathrm{~m}$ (Chrompack, Middelburg, the Netherlands).

\subsection{Off-Line Sampling/Splitless Desorption}

Splitless transfer of the analytes from the preconcentration trap to the GC system is in principle the most sensitive and powerful method of air analysis. It is especially suited for environmental analysis where maximum sensitivity in a minimum time is required since solutes are generally present at extremely low concentrations. For splitless desorption, the Gerstel TDS-2 system was used in its unmodified form. A schematic overview of the experimental set-up is shown in Figure 4. The TDS-2 system contains 2 valves which control the split/splitless state of the system. The four different flow modes are listed in Table 1. 


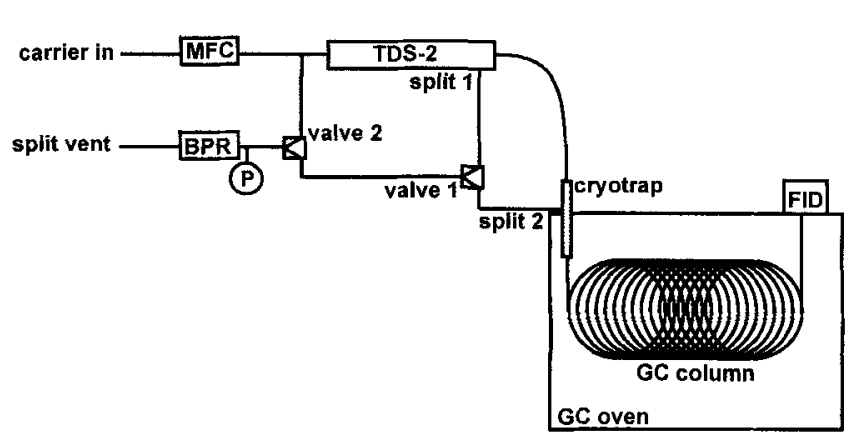

Figure 4. Schematic overview of the original configuration of the Gerstel TDS-2 system.

Table 1. Flow modes of the TDS-2 thermal desorption system.

Flow mode $\quad$ Valve 1 $\quad$ Valve 2

Split desorption

Splitless desorption

Split injection

Splitless injection

Splitless transfer of the analytes from the preconcentration trap to the column consists of two subsequent steps: the analytes are first desorbed splitless to the CIS-3 which is kept at $-150{ }^{\circ} \mathrm{C}$ during desorption to trap all the analytes. When desorption is complete, the TDS-2 is cooled down and the system is switched to splitless injection. The CIS-3 is heated to $350^{\circ} \mathrm{C}$ at a rate of $12 \%$ to transfer the analytes onto the column. After the splitless time (here selected to be $2.13 \mathrm{~min}$ ) the system is switched to split injection/splitless desorption which is the neutral state. The CIS-3 is cooled down to ambient temperature. Apart from the FID detector an ECD detector and an HP5970B mass selective detector were also used to provide increased sensitivity and selectivity.

\section{Results and Discussion}

\subsection{Retention Behavior of Packed PDMS Traps}

The retention behavior of solutes on the packed PDMS trap was investigated for four solutes: decane, 1-octanol, 2-nonanone, and dodecane. First, the retention volume $\left(V_{\mathrm{r}}\right)$ and the plate number $(N)$ were determined for decane and dodecane. The measured $V_{\mathrm{r}}$ values were then compared with values calculated from the equilibrium constant $(K)$ given in eq. (4). The temperature $(T)$ was varied between $30^{\circ} \mathrm{C}$ and $250^{\circ} \mathrm{C}$, the flow rate was varied between 100 and $2500 \mathrm{ml} / \mathrm{min}$. Pressure and temperature corrected flow rates were calculated by:

$$
F_{\text {corr }}=F^{0} \times \frac{1}{P_{0}} \times \frac{T}{298} \times \frac{3}{2} \times\left[\frac{\left(\frac{P_{\mathrm{i}}}{P_{0}}\right)^{2}-1}{\left(\frac{P_{\mathrm{i}}}{P_{0}}\right)^{3}-1}\right]
$$

Where: $F_{\text {corr }}=$

$$
F^{0}=
$$$$
P_{0}=
$$$$
P_{\mathrm{i}}=
$$$$
T=
$$

\section{Temperature and pressure corrected} flow rate, $\mathrm{ml} / \mathrm{min}$ Flow under standard conditions ( $P=1$ bar and $T=298 \mathrm{~K}$ ), $\mathrm{ml} / \mathrm{min}$

$P_{0}=\quad$ Absolute pressure at trap outlet, bar

$T=\quad$ Temperature of the trap, $\mathrm{K}$

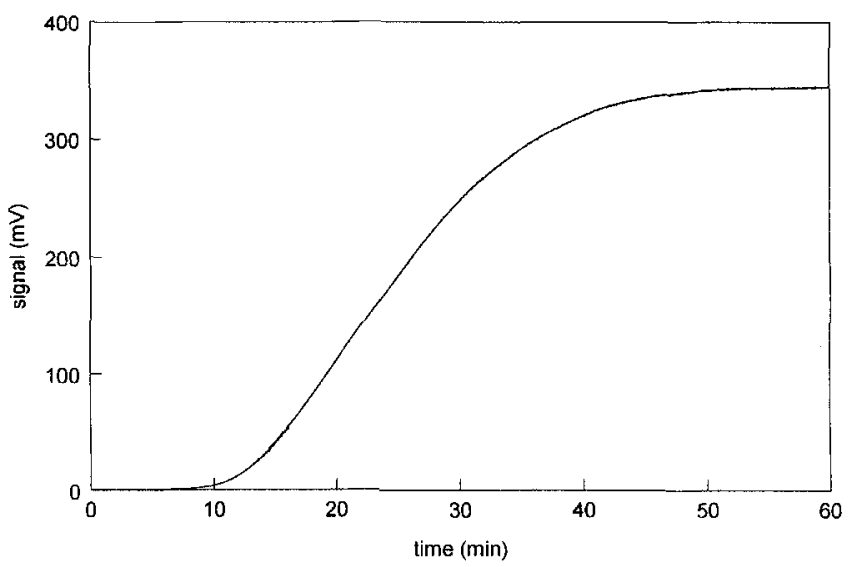

Figure 5. Experimental breakthrough curve for decane at $30^{\circ} \mathrm{C}$ at a flow rate of $148 \mathrm{ml} / \mathrm{min}$.

A typical breakthrough curve is shown in Figure 5. From these curves the first $\left(M_{1}\right)$ and second $\left(M_{2}\right)$ statistical moments were calculated on a computer using software written in-house. From these values $V_{\mathrm{r}}=M_{1} \times \mathrm{F}_{\text {corr }}$ and $N=M_{1}^{2} / M_{2}$ were calculated. Experimental equilibrium constants were calculated with:

$K_{\exp }=\beta\left(\frac{V_{r}}{V_{0}}-1\right)$

The calculated values were then compared to the values predicted by eq. (4). In Figures 6A and 6B the experimentally determined equilibrium constants for decane and dodecane are shown together with the theoretical line predicted by eq. (4). Each point in these figures is the average of 24 experiments at 8 different flow rates. Experiments showed that the flow rate does not affect the equilibrium constant. As can clearly be seen from Figures 6A and $6 \mathrm{~B}$, the experimental results are in good agreement with theory. Hence, the retention volume of the PDMS traps can be accurately predicted.

Since the equilibrium constants of the alkanes appear to be in good agreement with the values predicted by eq. (4), equilibrium constants for other solutes can, in principle, be calculated using published Kovats retention indices. This was done for 1-octanol and 2-nonanone for which the retention indices (at $140^{\circ} \mathrm{C}$ ) are 1051.50 and 1073.96 respectively, as was found in the Sadtler retention index library [23]. Figures $7 \mathbf{A}$ and $\mathbf{7 B}$ show the equilibrium constants for 1 -octanol and 2-nonanone with the theo- 

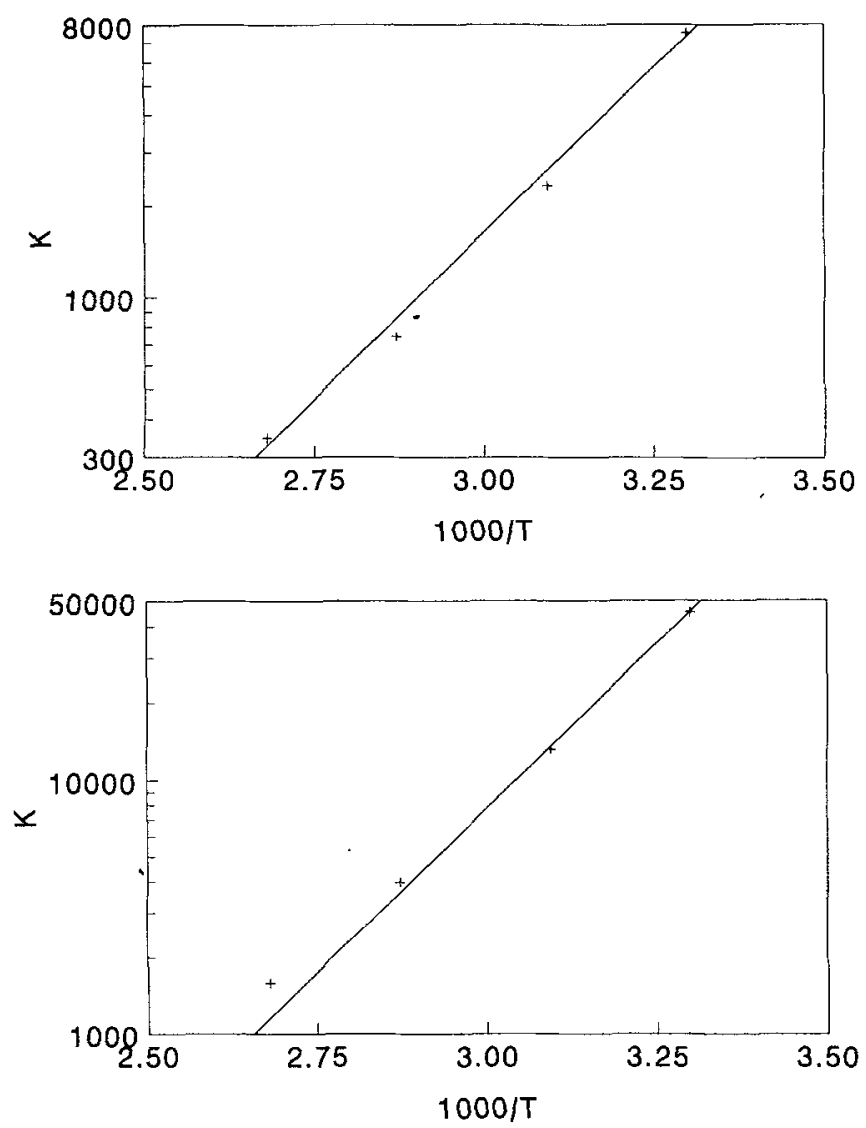

Figure 6. Equilibrium constant of decane (A) and dodecane (B).

retical line calculated from the retention indices. Each experimental point is the average of 15 experiments.

From Figures 7A and 7B it is clear that there is a slight deviation between the theoretical line and the experimental points. This error could be due to the fact that the retention indices taken from literature were determined at a temperature of $140{ }^{\circ} \mathrm{C}$ $(1000 / T=2.4)$. Use of this value at other temperatures may lead to an error in the predicted $K$ values.

A second parameter that affects the breakthrough volume of the packed sorbent trap is the plate number. Experimental plate numbers were determined for the four components. This is shown in Figure 8 where also the Knox equation for decane $\left(D_{\mathrm{m}}=6.23 \mathrm{~mm}^{2} / \mathrm{s}[21]\right)$ is shown. In this graph the experimentally observed plate numbers are always higher than the Knox equation predicts. Although the exact reason for this observation is yet unknown, the deviation observed might be due to the occurrence of turbulent flow in the packed bed. According to theory, turbulence starts to occur at a Reynolds number as low as 1 and is complete at a Reynolds number of roughly 100 [24]. This corresponds with flow rates of $22-2200 \mathrm{ml} / \mathrm{min}$. As turbulence enhances mass transfer in the mobile phase, turbulence will manifest itself by an increased plate number. This effect is desired since a higher plate number results in an increased retention volume. From this it can be concluded that the Knox equation can be used as a safe limit to predict the minimum number of plates the trap will contain. The breakthrough volumes calculated with theoretical $N$ values will again be smaller than the actual $V_{\mathrm{b}}$.
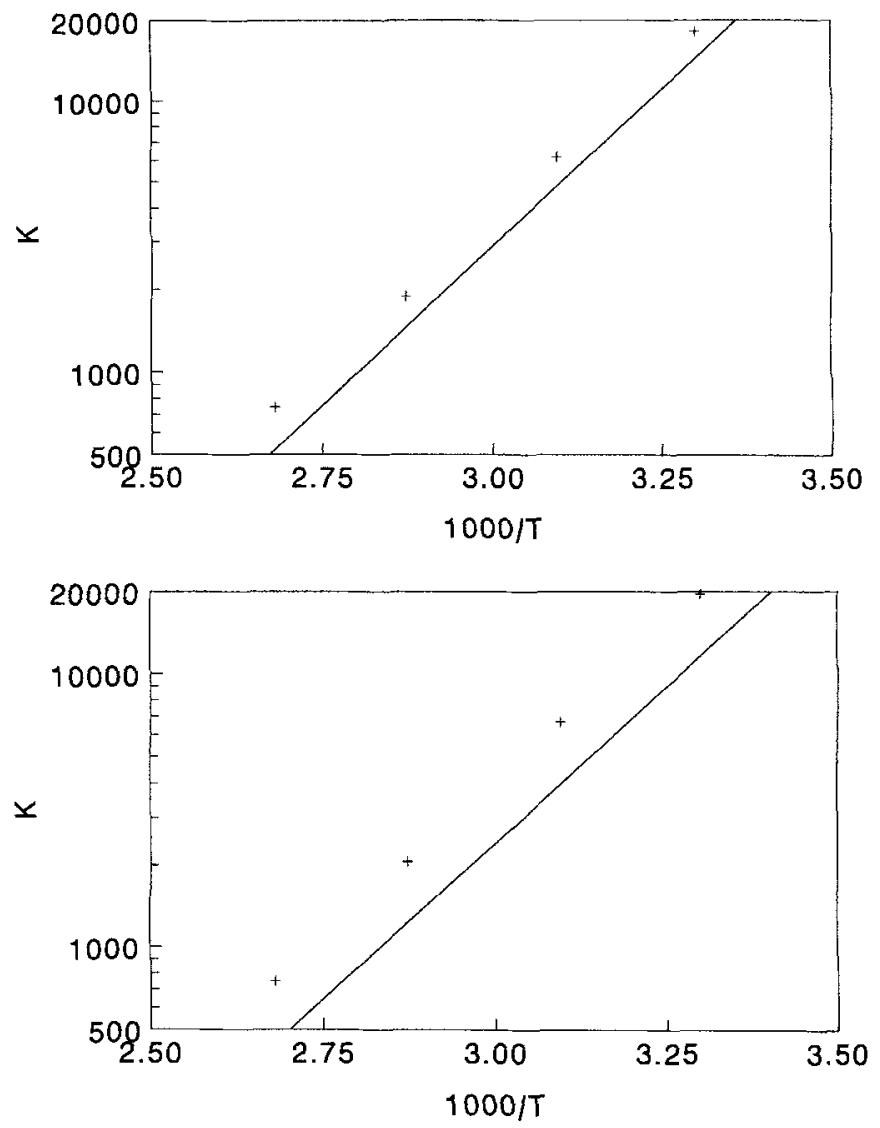

Figure 7. Equilibrium constant of 2-nonanone (A) and 1-octanol (B)

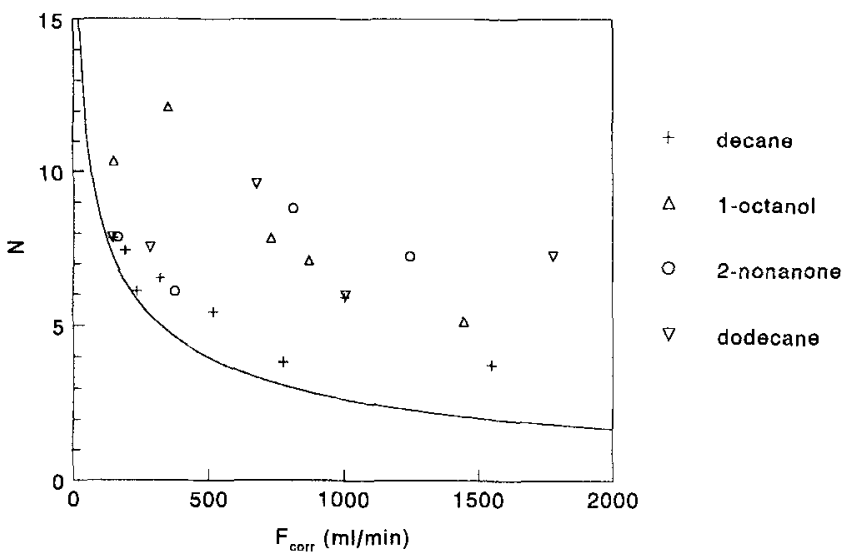

Figure 8. Plate numbers versus flow rate for the four solutes. The drawn line is the Knox equation for decane.

In conclusion, it is possible to calculate theoretical breakthrough volumes for PDMS traps. Experiments showed that the experimental breakthrough volumes are somewhat larger than those obtained theoretically. The theoretical value can therefore be used as a safe limit in method development.

\subsection{Split Desorption - Analysis of Natural Gas}

The on-line sampling system was used to analyze natural gas samples. In the first experiment, natural gas was sampled during 1 minute at a flow rate of $560 \mathrm{ml} / \mathrm{min}$. The TDS-2 was cooled to $15{ }^{\circ} \mathrm{C}$ to enhance the breakthrough volume. Under these condi- 
Table 2. Determination of alkanes in natural gas.

\begin{tabular}{lll}
\hline Component & Concentration (exp. I) & Concentration (exp. II) \\
\hline octane & $82 \mathrm{mg} / \mathrm{m}^{3}$ & 1 \\
nonane & $15 \mathrm{mg} / \mathrm{m}^{3}$ & 1 \\
decane & $3.2 \mathrm{mg} / \mathrm{m}^{3}$ & $3.1 \mathrm{mg} / \mathrm{m}^{3}$ \\
undecane & $0.38 \mathrm{mg} / \mathrm{m}^{3}$ & $0.41 \mathrm{mg} / \mathrm{m}^{3}$ \\
dodecane & 2 & $34 \mu \mathrm{g} / \mathrm{m}^{3}$ \\
tridecane & 2 & $2.7 \mu \mathrm{g} / \mathrm{m}^{3}$ \\
\end{tabular}

${ }^{1}$ not sampled quantitatively

2 not detected

tions for octane the calculated $V_{\mathrm{r}}$ is $954 \mathrm{ml}$ and the $5 \%$ breakthrough volume is $588 \mathrm{ml}$. Hence octane is the first component that is trapped quantitatively. Since the analytical column contains the same stationary phase as the preconcentration device, all peaks eluting after octane can be considered as sampled quantitatively. The chromatogram is shown in Figure 9.

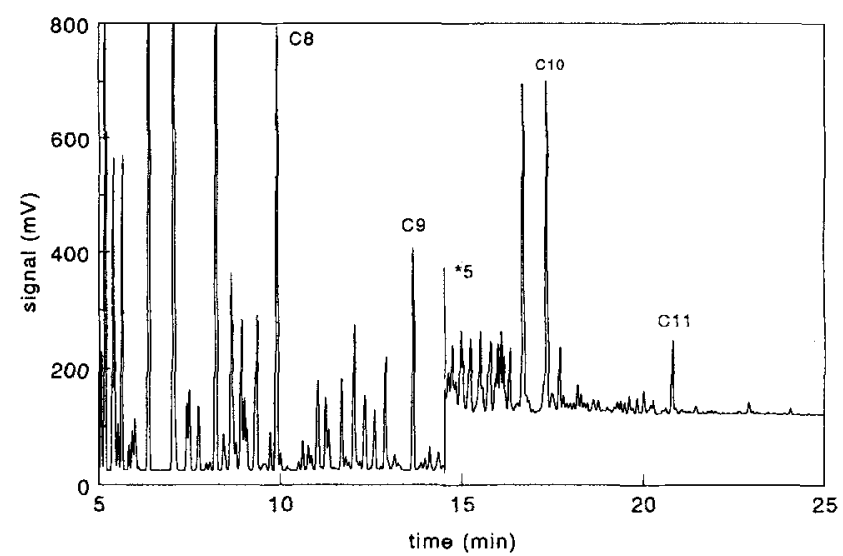

Figure 9. Chromatogram of natural gas $(560 \mathrm{ml})$. Detector: FID. $P_{\mathrm{i}}: 2.46$ bar, split: $77 \mathrm{ml} / \mathrm{min}$. Column: CP SIL5CB, $35 \mathrm{~m} \times 320 \mu \mathrm{m} \times 1.1 \mu \mathrm{m}$. GC: $40^{\circ} \mathrm{C}$ $(3 \mathrm{~min})-5 \% \min -300^{\circ} \mathrm{C}$.

In a second experiment, natural gas was sampled for $10 \mathrm{~min}$ at a flow rate of $550 \mathrm{ml} / \mathrm{min}$. During this experiment the TDS-2 was kept at $0{ }^{\circ} \mathrm{C}$. Under these conditions the $5 \%$ breakthrough volume for decane is 10.7 liter. The chromatogram of this analysis is not shown. From both natural gas analyses the alkanes were quantified. The results are shown in Table 3 .

\subsection{Splitless Desorption - Environmental Analysis}

In environmental analysis maximum sensitivity is generally required. Splitless transfer of the components desorbed from the trapping bed allows the injection of $100 \%$ of the components trapped from an air sample. As an initial experiment air was sampled off-line in a rural area near the city of Eindhoven. A low flow air sampler model LFS113DC (Gillian Instrument Corporation, West Caldwell, NJ, USA) was used to sample air through the packed PDMS tube (off-line) for $114 \mathrm{~min}$ at a flow rate of $460 \mathrm{ml} / \mathrm{min}$. An air sample of 52.4 liters was taken. At the time of sampling the temperature was $24{ }^{\circ} \mathrm{C}$. Under these conditions the $5 \%$ breakthrough volume of tetradecane is 108 liters. This compound is thus the first solute trapped quantitatively. The analytical column for this separation was a CP Sil 5 CB column
(Chrompack) which was $20 \mathrm{~m}$ long, $0.32 \mathrm{~mm}$ i.d., and had a film thickness of $0.25 \mu \mathrm{m}$. The GC program started at $30^{\circ} \mathrm{C}$ for $3 \mathrm{~min}$. The temperature was then ramped to $300{ }^{\circ} \mathrm{C}$ at $8 \% \mathrm{~min}$. The chromatogram obtained from this analysis is shown in Figure 10.

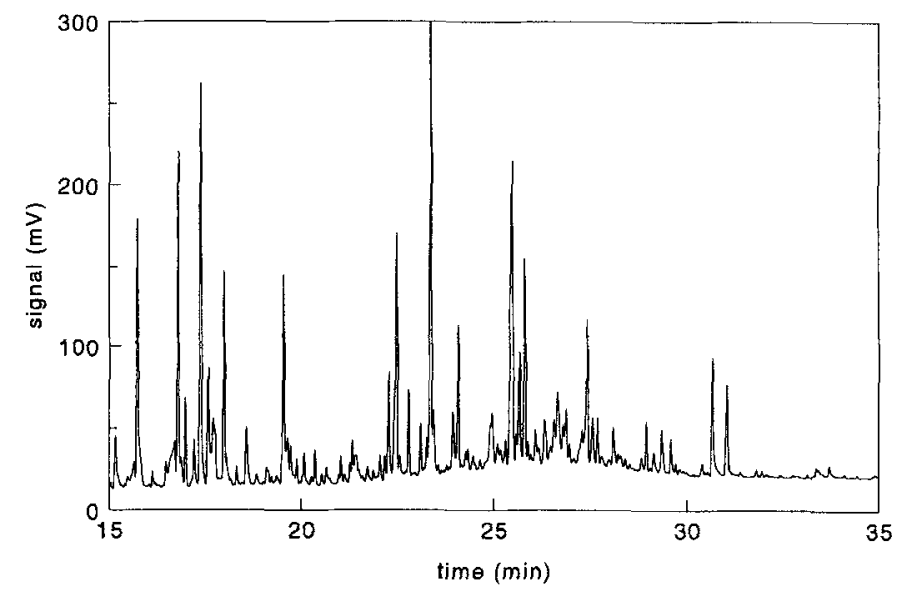

Figure 10. Analysis of home air (52.4 1). Only the quantitatively sampled part (tetradecane and higher) is shown. Detector: FID. Desorption flow rate: $200 \mathrm{ml} / \mathrm{min}$. $P_{\mathrm{i}}: 2$ bar. Column: CP SIL5CB, $20 \mathrm{~m} \times 320 \mu \mathrm{m} \times 0.25 \mu \mathrm{m}$. GC: $30^{\circ} \mathrm{C}(3 \mathrm{~min})-8 \% \mathrm{~min}-300^{\circ} \mathrm{C}$.

For environmentally relevant applications a mass selective detector (MSD) is imminent. The HP5970 MSD was employed to determine the 16 priority PAH's in air. The MSD was equipped with a capillary direct interface. The column used was again a CP Sil 5 CB column (Chrompack) which was $13 \mathrm{~m}$ long, $200 \mu \mathrm{m}$ i.d., and coated with a film of $0.33 \mu \mathrm{m}$. For quantification purposes a certified PAH standard from Supelco (Bellefonte, PA, USA) was used. Laboratory air was sampled for $60 \mathrm{~min}$ at a flow rate of $2.51 / \mathrm{min}$. The MSD is operated in the SIM mode. The chromatogram for the PAH analysis is shown in Figure 11 and the quantitative data are listed in Table 3.

As can be seen from Figure 11, a good chromatogram is obtained. Solutes as heavy as benzo $[a]$ pyrene can be rapidly and quantitatively desorbed from the PDMS particles. The detection limit of the present system is roughly $0.1 \mathrm{ng} / \mathrm{m}^{3}(0.1 \mathrm{ppt})$. The heaviest three PAH's (14-16) were not detected at this level. For comparison to other data on PAH's it is important to note that the values reported here relate to the gaseous phase, i.e. components adsorbed on particles in air were not measured. This was checked in a separate experiment where a glass wool filter was placed before the PDMS trap. This experiment yielded identical quantitative results. Hence it was concluded that during air sampling particulate matter passes through the PDMS tube.

Since the PDMS material exhibits clear advantages over adsorption materials with regard to polar solutes, it was attempted to determine nitro-PAH's in ambient air. The level at which these solutes are present is considerably below $0.1 \mathrm{ng} / \mathrm{m}^{3}$, i.e. the MSD is not sensitive enough for this analysis, not even in the SIM mode. An ECD detector was used to determine 6-nitro-PAH's spiked in grade 7.0 nitrogen to a level of $4 \mathrm{ng} / \mathrm{m}^{3}(4 \mathrm{ppt})$. The chromatogram of this analysis is shown in Figure 12. Under the analytical conditions used, the nitro-PAH's can be rapidly and quantitatively desorbed and analyzed by the chromatographic 


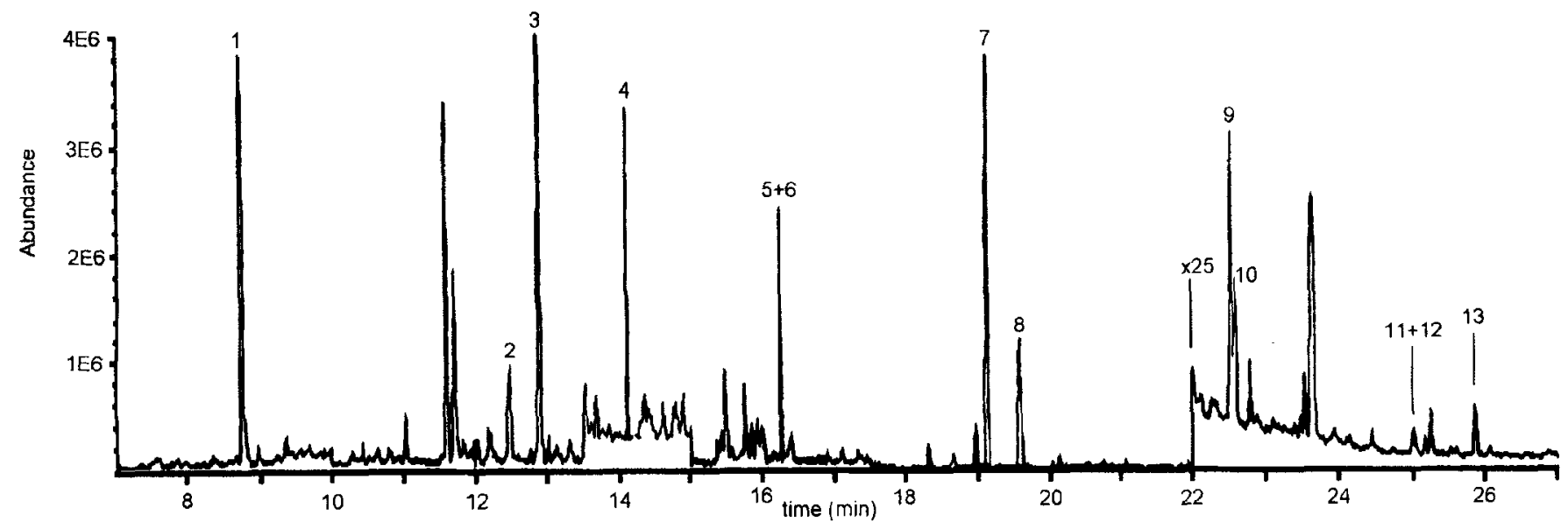

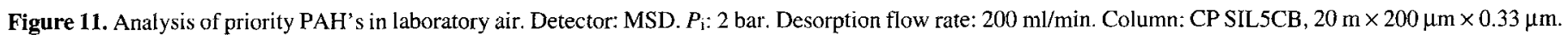
GC: $40^{\circ} \mathrm{C}(3 \mathrm{~min})-10^{\circ} / \mathrm{min}-325^{\circ} \mathrm{C}$. Peak identification see Table 3.

Table 3. Analysis of PAH's in laboratory air - quantitative data.

\begin{tabular}{|c|c|c|c|c|c|}
\hline $\begin{array}{l}\text { Peak } \\
\text { number }\end{array}$ & Component & lons monitored & $\begin{array}{l}\text { Conc. } \\
{\left[\mathrm{ng} / \mathrm{m}^{3}\right]}\end{array}$ & $\begin{array}{l}R I \\
{[23]}\end{array}$ & $V_{\mathrm{b}}$ \\
\hline 1 & Naphthalene ${ }^{1}$ & $128,102,64$ & 93 & 1187.75 & 11.29 \\
\hline 2 & Acenaphthylene ${ }^{1}$ & $152,126,76$ & 34 & 1428.30 & 109 \\
\hline 3 & Acenaphthene & $154,126,76$ & 129 & 1460.73 & 150 \\
\hline 4 & Fluorene & $166,115,83$ & 89 & 1547.92 & 385 \\
\hline $5+6$ & Phenanthrene & $178,152,89$ & $88^{2}$ & & \\
\hline & Anthracene & & & & \\
\hline 7 & Fluoranthene & $202,101,88$ & 61 & & \\
\hline 8 & Pyrene & $202,101,88$ & 38 & & \\
\hline 9 & Benzo[a]anthracene & $228,114,101$ & 4.3 & & \\
\hline 10 & Chrysene & $228,114,101$ & 2.3 & & \\
\hline $11+12$ & Benzo[b]fluoranthene & $252,126,113$ & $0.42^{2}$ & & \\
\hline & Benzo $[k]$ fluoranthene & & & & \\
\hline 13 & Benzo $[a]$ pyrene & $252,228,126$ & 0.50 & & \\
\hline 14 & Indeno[123-cd]perylene & $276,138,124$ & $<0.1$ & & \\
\hline 15 & Dibenzo[ah]anthracene & $278,139,125$ & $<0.1$ & & \\
\hline 16 & Benzo|ghi]perylene & $276,138,124$ & $<0.1$ & & \\
\hline
\end{tabular}

${ }^{1}$ Compound was not sampled quantitatively.

${ }^{2}$ Compounds were not completely resolved. Concentration is the sum for both components.

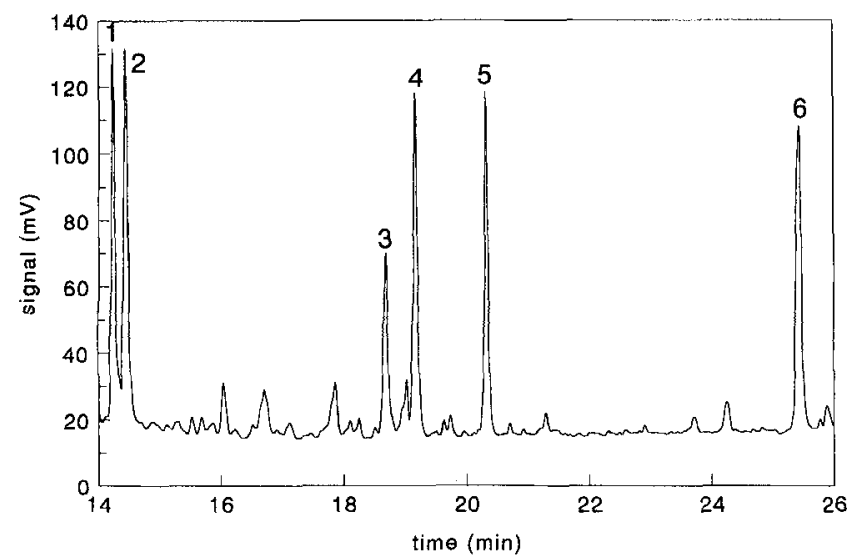

Figure 12. Analysis of nitro-PAH's spiked to a level of $4 \mathrm{ng} / \mathrm{m}^{3}$ in clean nitrogen. Detector: ECD. Conditions as listed in Figure 10. Peak assignment: 1, 1-nitronaphthalene; 2, 2nitronaphthalene; 3, 9-nitroanthracene; 4, 5-nitroacenaphthene; 5, 2-nitrofluorene; 6, 1-nitropyrene. system. Unfortunately, the ECD does not exhibit adequate selectivity for real-world samples, i.e. too many interfering compounds are present.

\section{Conclusions}

The system described in this report, based on packed PDMS preconcentration traps, shows evident advantages over current air preconcentration methods. The PDMS material is much more inert than a standard adsorbent material. Moreover, for PDMS as a preconcentration material it is possible to calculate breakthrough volumes from theoretical equations. Finally, due to the low pressure drop over the trap and the occurrence of turbulence, very high sampling flow rates can be applied.

The possibility to use high desorption flow rates allows thermal desorption at reduced temperatures, thereby minimizing the risk of sample and sorbent degradation/alteration. The capability of low-temperature desorption together with the intrinsic inertness of PDMS gives excellent results for the analysis of polar (nitroPAH's), and high MW (benzo[a]pyrene) solutes in gaseous samples.

With the present system the detection limit is $0.1 \mathrm{ng} / \mathrm{m}^{3}$ whereas the maximum allowable concentration is approximately $100 \mathrm{mg} / \mathrm{m}^{3}$. This extremely wide concentration range is the result of the possibility to use both split and splitless transfer of the analytes.

\section{References}

[1] Y.Z. Tang, Q. Tran, P. Fellin, and W.K. Cheng, Anal.Chem. 65 (1993) 1932.

[2] K. Grob, A. Artho, C. Frauenfelder, and I. Roth, J. High Resol. Chromatogr. $13(1990) 257$.

[3] R.T. Talasek and K.E. Daugherty, J.Chromatogr.A 639 (2) (1993) 221.

[4] Y. Yokoushi and M. Sano, J.Chromatogr. 473 (1991) 297.

[5] S.F. Patil and S.T. Lonkar, J.Chromatogr.A 684 (1) (1994) 133.

[6] V. Simon, M.L. Riba, A. Waldhart, and L. Torres, J. Chromatogr.A 704 (2) (1995) 465.

[7] J.E. Bunch, E.D. Pellizzari, J.Chromatogr. 186 (1979) 811.

[8] B.V. Burger and Z. M. Munro, J.Chromatogr. 370 (1986) 449. 
[9] J. Roeraade and S. Blomberg, J. High. Resol. Chromatogr. 12 (1989) 138. [10] S. Blomberg and J. Roeraade, J. High. Resol. Chromatogr. 13 (1990) 509.

[11] K. Ventura, M. Dostál, and J. Churacek, J.Chromatogr. 642 (1993) 379.

[12] J.F. Pankow, Anal.Chem., 60 (1988) 950.

[13] C. Bicchi, A. D'Amato, F. David, and P. Sandra, J. High. Resol. Chromatogr. 12 (1989) 316.

[14] E.K. Ortner and E.R. Rohwer, J. High. Resol. Chromatogr. 19 (1996) 339.

[15] M.S. Krieger and R.A. Hites, Environ.Sci.Technol. 26 (1992) 1551

[16] K. Kawata, H. Mukai, and A. Yasuhara, J.Chromatogr.A 710 (1995) 243.

[17] P. Lövkvist and J.Å. Jönsson, Anal.Chem. 59 (1987) 818.

[18] W. Millen and S. Hawkes, J.Chromatogr.Sci. 15 (1977) 148.
[19] G.J. Kennedy and J.H. Knox, J.Chromatogr.Sci. 10 (1972) 549.

[20] G. Guiochon, Anal.Chem. 52 (1980) 2002.

[21] E.N. Fuller, P.D. Schettler, and J.C. Giddings, Ind. Eng. Chem. 58 (15) (1966) 19

[22] K. Grob and A. Habich, J. Chromatogr. 321 (1985) 45.

[23] The Sadtler Standard Gas Chromatography Retention Index Library, Sadtler Research Laboratories, Philadelphia, 1985.

[24] J.C. Giddings, Unified Separation Science, John Wiley and Sons, New York, 1991.

Ms received: October 16, 1996; accepted: March 11, 1997 